\title{
Roundtable Discussion
}

\section{Fifty Years of the Journal HSR: Informing Policy and Practice}

Jacqueline Zinn, Patrick S. Romano, Gordon DeFriese, Stephen M. Shortell, Harold S. Luft, and Ann B. Flood

Jackie Zinn and Patrick Romano: As indicated in Lisa Simpson's commentary that appears in this issue of $H S R$ (Simpson 2017), health services research, the field, and HSR, the journal, more or less grew up together. As we are celebrating the 50th anniversary of $H S R$, we would like you to reflect back on your time as EIC at the journal and your experience in the field. What are some of the most important ways that HSR has impacted the field, either in redefining the conceptual framework or the methods or in expanding and strengthening the science and the scientists?

Steve Shortell: An esteemed colleague once referred to HSR as the "workhorse" journal of the field. At first, I took a bit of an offense to this description and pushed further to learn what he meant. His response was essentially that $H S R$ provided the breadth and volume of content to continuously engage the field of health care policy, practice, and academia. The person went on to say that HSR was always among the first choices for his doctoral students to submit their papers. So if $H S R$ has a "niche," it may be in the broad-based interdisciplinary nature of its topics, methods, and readership.

Two examples from the late 1990s and early 2000s serve as examples. The first was the Journal's role in highlighting the importance of qualitative methods and mixed qualitative/quantitative methods reflected in the seminal 1999 issue edited by Tom Rundall. Among other contributions, this issue developed detailed explicit rigorous criteria by which qualitative work might be evaluated. These criteria are now used widely by all journals in evaluating such work. This special issue was followed in 2007 by a follow-up assessment of advances in qualitative methods application in health services research by Elizabeth Bradley and colleagues and work applying "fuzzy set" analysis by 
Thygeson and colleagues in 2011. The 1999 issue also provided a methods template for the Robert Wood Johnson Foundation-funded Community Tracking Studies led by Paul Ginsburg and staff that provided important "grassroots" information on the changing health care system for many years. The special issue was also drawn on by doctoral training programs in health services research and health policy analysis as students and faculty alike increasingly recognized the contribution that qualitative studies could make in providing knowledge and insights in their own right but also for generating hypotheses that might eventually be able to be tested with large-scale data sets amenable to quantitative analysis.

The second development was the increase in the number of articles dealing with quality of care and performance improvement. As health care costs were continuing to increase, policy makers were beginning to question what the country was getting for its extensive investment. This question was made more salient by two path-breaking Institute of Medicine (now National Academy of Medicine) reports-To Err Is Human and Crossing the Quality Chasm. The first documented the extent of medical errors and mishaps in the system, and the second report underscored the pervasiveness of the problem along with recommendations of what it would take to develop a high-performing health care system. Along with clinically oriented journals, HSR played a leading role in publishing some of the early work on assessing and improving the quality of care, an issue that remains at the forefront of health policy and practice today.

It is also important to note that the Journal's impact has been enhanced by its designation as one of the official journals of AcademyHealth (previously the Association for Health Services Research). This partnership provides the Journal with ready access to over 2,000 members and, in particular, to younger investigators entering the field.

Gordon DeFriese: As would be expected, the evolution of HSR closely followed the growth and development of the field of health services research.

Address correspondence to Jacqueline Zinn, Ph.D., Department of Risk, Insurance and Healthcare Management, Temple University, Philadelphia, PA 19122; e-mail: zinn@temple.edu. Patrick S. Romano, M.D., is with the Division of General Medicine, University of California at Davis, Davis, CA. Gordon DeFriese, Ph.D., is with the Department of Social Medicine and Epidemiology, University of North Carolina at Chapel Hill, Chapel Hill, NC. Stephen M. Shortell, Ph.D., is with the Blue Cross of California Distinguished Department of Health Policy and Management, School of Public Health and Haas School of Business, University of California, Berkeley, CA. Harold S. Luft, Ph.D., is with the Palo Alto Medical Foundation Research Institute, Palo Alto, CA. Ann B. Flood, Ph.D., is with the Department of Radiology, Community and Family Medicine, Dartmouth Institute for Health Policy and Clinical Practice, Lebanon, NH. 
The early publications in these pages reflected not only the predominant focus on the financial and organizational challenges of the hospital industry but the early attempts at regional planning for health care services in a broader sense. To a great extent, the development of both the questions being addressed and the methods for their pursuit were dependent on the availability of data and technologies for their analysis. After Wennberg and others began to show, through initial publication in Science (1973) and then later in Scientific American (1982), how medical practice variation in New England could be demonstrated with Medicare data, and as availability of administrative data on a state or regional basis became a reality, more and more researchers began to use such data to reveal patterns of care and compare clinical outcomes. This work helped attract Congressional support for expanding the work of the National Center for Health Services Research and agencies (e.g., the AHRQ) that followed. We were excited to be able to publish in HSR Lucien Leape's initial 1989 study of surgical care variation using a similar methodological approach. Similarly, some of the early methodological achievements of the UCLA/ RAND group helped underscore the rapidly growing sophistication of the work taking place in this field. This rapidly expanding volume of work by impressive teams of investigators from multiple disciplines began not only to provide data-driven policy analyses addressing some of the most important macrolevel questions related to health care but also to generate many new methods and measurement tools for understanding the behavior of those who need and use health care services in a variety of settings.

Many of us who were engaged in this field in its early days can remember having to explain over and over again to academic colleagues, as well as family and friends outside the field, exactly what was meant by the term "health services research." Twenty years later, it was both amusing and gratifying to see so many young faculty in a wide range of disciplines listing "health services research" among their primary fields of interest and accomplishment. Moreover, if one identified with this field, it was notable when one or more publications in $H S R$ were among those submitted for consideration as tenure and promotion decisions were being made. The effort by the AHSR (and later AcademyHealth) to award annual recognition for the most outstanding publications in this field helped to ensure the attention to HSR and other publications where these contributions were published.

Jackie Zinn and Patrick Romano: From an editorial perspective, what were the major challenges, issues, and decisions that arose during your tenure?

Gordon DeFriese: I was not the first, but the fourth or fifth, editor of $H S R$, depending on how one counts them. The initial editors were various staff 
persons from the American Hospital Association. Years ago, soon after taking the editorship myself, I had the good fortune to have a discussion with Kerr L. White, M.D., about the early history of HSR. White was asked in the late 1960s to help design a new journal to be sponsored by the American Hospital Association that would appear about the time Medicare and Medicaid legislation, and the Partnership for Health Amendments, were enacted. Discussions in Chicago apparently were headed in the direction of naming the journal "The Journal of Hospital Studies," or something to that effect. Dr. White, whose vision for the field was considerably broader than others, and who had been the chairman of the study section on health services research of the U.S. Public Health Service, insisted that the journal be called "The Journal of Health Services Research.” The first editor of the journal was William S. Spector, who served from 1966 to 1974 . He was succeeded by various persons over the years from 1974 to 1978, when Gary Bisbee, who was the then president of the Hospital Research and Educational Trust (HRET) at the American Hospital Association, took over editorial responsibilities. In 1979, Bisbee asked me to become the book review editor working with him, which I did for about three years. Then, as he was ready to give up the position of editor, he asked me to become the editor in 1984. This was the first time that the editorship of the journal would be assigned to someone outside of HRET/AHA.

We decided at that time to no longer have a book review section as it seemed to always happen that by the time we could get a review in print, the book would often be ready for revision or other books would seem more current and salient in terms of contemporary health care issues of concern to the field.

One of the first things we agreed to do after I took over the editorship was to expand the journal from four to six issues per year. John Marshall, then the director of the National Center for Health Services Research, assured that the funding to support this expansion was available in order to provide an avenue for publication of some of the most important science in this emerging interdisciplinary field.

The journal was published by HRET, with a subcontract to the University of Michigan Press in Ann Arbor to handle the day-to-day editorial production work of publication. I handled all correspondence with authors and reviewers from my office at the Cecil G. Sheps Center for Health Services Research at the University of North Carolina at Chapel Hill. The 13 years of my tenure in this position were clearly some of the most enjoyable and exciting years of my professional life. During this time, many of us were involved in starting the new Association for Health Services Research (AHSR), and 
$H S R$ was adopted as the "official journal" of the new Association. "HSR" (as we now refer to it) has remained a membership benefit of the Association through the years, and there is a close relationship that has been important to both the Association (later AcademyHealth) and HSR.

Steve Shortell: When I assumed the editorship of HSR in 1996, I had the unique opportunity and good fortune to build on the three decades of the Journal's success under previous leadership, including Gordon DeFriese. It was already a leading established journal, and the main challenge was to increase our ability to attract the best authors and papers in the face of increasing competition and a fast-moving health care sector of issues to be addressed. Among the competing journals vying for authors and readers were Medical Care, founded in 1962 and the official journal of the Medical Care section of the American Public Health Association; Medical Care Research and Reviere, founded in 1947; The Milbank Quarterly, founded in 1923 and sponsored by the Milbank Memorial Fund; Inquiry, founded in 1964 and the official journal of the national Blue Cross/Blue Shield Association; and, of course, Health Affairs, founded in 1982 and sponsored by Project Hope. During this time, the Journal of the American Medical Association (JAMA) and the New England Journal of Medicine also began to increase their coverage of health policy/health services delivery issues for their largely physician audiences.

In response, we developed a series of small but, I think, re-enforcing changes. These included expanding the associate editorial team and number of reviewers; developing an explicit statement of our vision, mission, and values; organizing the cover content of articles by salient topic areas such as access/use, cost, quality and outcomes, methods, and policy impact; and initiating a process of assessing the quality of reviews and reviewers with feedback. Perhaps the most important of these was our explicit statement of our vision, mission, and values which guided and motivated all that we did. It appears on the inside front page of every issue. While most journals have a mission statement or it can be inferred from what is said on their website, few have a statement of their vision - what they aspire to become. Our vision at HSR as stated is to be "... the preferred forum ... and outlet ..." for original work that addresses the "... financing, organization, delivery, and outcomes of health services." The values statement has served as a guide for our reviewers and is also reflected in sharing examples of outstanding reviews.

Special Issues also presented challenges. These included deciding on how many and on what topics, selecting a Special Issue editor(s), soliciting open submissions or pre-identifying relevant authors, arranging financing, 
and monitoring the timeline. Yet, as noted above in the case of qualitative research, many of the special issues have had significant impact on the field.

Hal Luft and Ann Flood: The practice of having dual editors in chief for HSR began with our tenure, in 2002 (i.e., Hal Luft and Ann Flood as co-editors in chief [EICs]). The primary impetus for dual leadership was not to reduce the workload (although that may have had positive indirect consequences on increasing the throughput and responsiveness of the first round of editorial decisions). It was instead to ensure the dedication of $H S R$ to the multidisciplinary focus of health services research by having editorial leadership reflecting at least two complementary disciplines, in our case: health economics and organizational sociology related to health care services.

Two "environmental" changes were happening at the same time that influenced our editorial process: (1) It was time for HSR to move to an electronic process for submitting and reviewing manuscripts, and (2) there was growing recognition that health science/health services research should reflect upon ethical and other issues (i.e., who is responsible for the research and when a journal should decide not to allocate its "space" to publish work that has already been disseminated). The latter issues arose after a series of pronouncements by editors of major medical journals regarding the minimum ethical/scientific standards that any clinical study should adhere to if published in their peer-reviewed publications, as well as their concerns about "prior publication." This led us to ask: "Is health services research immune to these concerns and, if not, shouldn't there be a parallel standard for health services research published in our peer-reviewed journals?"

The online system we adopted using ManuscriptCentral led to userfriendly features and a reduction in time from submission to acceptance. We also recognized that, while every author hopes a manuscript is not rejected, even worse is a long-delayed rejection. Thus, when it was apparent to the EIC who assigned the manuscript that a submission had little chance of ultimate success, we sought to notify the author as quickly as possible. The electronic process also led to the incidental, but very important, return to the editors and associate editors of many editorial functions, which had-back in the paperintense days of processing manuscripts - devolved to assistants, for example, to choose reviewers when the original reviewers declined but offered other names. This improved the editorial process as it brought the accountability for science back to the editors, the reviewers, and the authors engaging fully in the peer review process.

The editorial leadership saw the challenges facing the medical journal editors and went above and beyond the usual role of soliciting and 
adjudicating important and excellent research within HSR's mission. We deemed it time to make explicit the expectations of our journal for meeting the scientific and ethical standards we wanted HSR's publications to exemplify. Three "big" changes resulted:

First, we decided to tackle head on the issue of authorship; that is, what should an "author" be expected to have contributed to a published article, and correspondingly, for what should each author be responsible in his or her article? Across the journals, there was not always agreement. Some were comfortable with the then-common practice of including as authors, on the one hand, those whose major role was obtaining funding or providing data, and on the other, those who recruited study subjects or estimated some regressions. The former typically benefitted with "authorships" from very senior people, the latter from very junior staff. When scientific misconduct occurs, however, every author is held equally responsible. $H S R$ decided to define authorship in terms of "responsibility," rather than "credit." In essence, authors are those responsible for the design and conduct of the research and for the drafting or critical revision of the manuscript. We ask each author to verify that they fulfilled these definitions with the knowledge that their declaration would be made public in online-only material connected to their article. We also tried to encourage authors to name important contributors who do not qualify as authors in an acknowledgment section to be included in the published article. For details, see the Authorship and Disclosure Form at http://www.hsr.org/ hsr/information/authors.jsp.

Second, we worked with several other health services/health policy journals to disclose any prior publication of the work in the submitted manuscript. Here, we collaborated with the other major journals in the field (see http:// www.hsr.org/hsr/information/authors/ppublication.jsp). Based on several meetings and written exchanges, major journals in our field published a joint statement about disclosure of prior publication (and what prior activities were likely [or not] to result in refusal to consider a manuscript for further publication). The intent was to have a policy whereby authors would be expected to be transparent in disclosing prior dissemination of their study findings, with the expectation that the journals would fairly evaluate whether this negated accepting the work (other things being acceptable) for publication. Importantly, each journal could decide whether or not specific types of prior dissemination would jeopardize subsequent publication in its pages.

Third, we took on other ethical considerations in parallel with our sister medical journals. For instance, we wanted people to disclose whether there had been any prior agreements with funders or other sponsors to review the 
paper and its results, particularly if they held rights to approve or revise the content. (See Disclosure policy at http://www.hsr.org/hsr/information/au thors.jsp.) While "Big Pharma" had been the major concern along these lines for medical journals, we discovered that governments - especially for government employees conducting research and for contract-funded projects-were most likely to curtail freedom to publish. Such constraints and clauses, if revealed, would not necessarily preclude our acceptance, but would be published in supplementary material. We tried tackling a few other issues along these lines-including trying to be much more transparent about the process and the likelihood of success and the timeframe for publication in our journal. These led to a series of editorials (see available online at http://www.hsr.org/ hsr/specialfeatures/editors.jsp) as well as a framing of a popular panel at the AcademyHealth ARM Meetings called "Publish or Perish: Meet the Editors."

Jackie Zinn and Patrick Romano: What makes an article outstanding in your view?

Ann Flood: What makes an article outstanding? (And perhaps most important, how and when can you know it's outstanding?) Taking the EIC's perspective literally, that is, when an article first reaches an EIC to make the initial "cut" to reject or review an article, how and how well can we recognize that an article is outstanding? "Outstandingly well written" is pretty easy. However, it is relatively rare that an article is truly exceptional when it first arrives in the EIC's hands; that is, it is so exceptionally well written, well grounded in the literature, well designed, and well executed that it doesn't even need peer review. Most genuinely benefit from undergoing constructive peer review. Regardless of the status pre- vs. postreview, an extremely well-prepared study may or may not be truly "outstanding," if by that we mean instead is that significantly changes the shape or content of future research or policies. In that case, such a designation can only be determined with hindsight, that is, after the significant impact has occurred. Then, the question becomes, "Did EICs and associate editors easily recognize the exceptional influence of the paper in advance?" Can EICs legitimately say, "I told you so!"?

Probably not. One reason for saying that comes from the annual experience in selecting HSR's Eisenberg article of the year from among the set of articles published in a given volume. Identifying the "best" in this context appeared to benefit from relooking at each article after it successfully navigated the peer review process. Selecting an outstanding article also benefitted from evaluating a set of articles in the context of looking for outstanding contributions to science or policy, and the one(s) that rise to the top depended in part on the set being considered. It also made a difference to have an 
interactive discussion with the other editors who were considering the articles from these perspectives, rather than from a go/no-go decision to publish.

Identifying true paradigm-shifting articles in health services research may be an unattainable, existential goal. One lesson I learned, while a graduate student looking at the historical context of the then-current theories in the field, is how much the "gods" who have developed ground-breaking new theoretical paradigms or lasting methodological or policy breakthroughs have actually rested on the backs of many others; that is, the wisdom behind their scientific breakthroughs looked much more iterative and gradual upon closer inspection. It was not always clear why some articles became known as "outstanding" when others had come to remarkably similar conclusions in previous work.

I offer a personal (and very humble) example about what has been a very "impactful" scientific study that involved work that both Hal and I had been conducting in slightly different contexts at Stanford. Hal and his colleagues were the first to publish a somewhat intriguing finding that the higher the "volume" of cases treated surgically at a hospital, the better the outcomes (Luft, Bunker, and Enthoven 1979). We, in a different and very unusually large database about surgical care, had the opportunity to examine the same question; we too found the same basic empirical evidence and posited an explanation that we simplified by reference to the aphorism, "Practice Makes Perfect"; that is, we argued that there were many mechanisms at the surgical but also the organizational level that led to having greater oversight and better processes for commonly seen cases that went along with processes that produced better outcomes (Flood, Scott, and Ewy 1984a,b). Hal and his colleagues, in another study focused on the same empirical association, posited a possible opposite explanation; they suggested that the observed association could be due to selective referral (Luft, Hunt, and Maerki 1987) (which we then tonguein-cheek said can be viewed as the mirror image of our explanation and so should be described as "Perfect Makes Practice" [Flood and Fennell 1995]), that is, that having a "perfect reputation" for achieving great outcomes brings patients to your door, thereby explaining the relationship.

$\mathrm{Hal}$, our colleagues, and I have largely moved on to research on other issues, but we remain convinced that both explanations (more cases lead to better outcomes and better outcomes lead to more cases) may be valid, although the relative importance of each may vary by condition or surgical procedure. More important, despite numerous articles exploring this empirical finding, the field still lacks fundamental understandings of the precise organizational and referral processes underlying those causal pathways. 
Is this an example of outstanding research since it helped spawn numerous studies on the topic? Or is there another reason that it has caught the attention of others and resulted in a "cloud" change? It is tempting to say it was therefore outstanding work, but its persistence seems puzzling to an economist or organizational sociologist.

The bottom line for those who want to create an outstanding article is this: If you want your work to make an important contribution, strive to be outstanding - that mission will be the best way to improve our science and our policies - but be prepared to instead have your work recognized as important by being an integral but modest step toward advancing knowledge. "Superstar quality" is no doubt oversold as an indication of work that can truly make a difference. And work that will significantly influence future research is hard to recognize and predict in advance — even when it's your own!

Hal Luft: In my opinion, there are two broad criteria one could use to consider an article as an "outstanding" contribution to our field of health services research, which at its core is applied. One is whether the article influences policy or practice - things that affect real people and organizations. A second is whether it changes the way researchers, or even broader audiences, think about issues or how to solve problems.

In the first realm, one can often point to articles with findings that gave a clear answer as to what one should do in specific circumstances. The challenge, however, is finding the one article that provided the definitive evidence "settling the argument," or at least allowing policy makers to move forward with a plan. Those articles sometimes exist, but usually as the result of a massive project designed to answer the question at hand. Being able to have the funding for the project meant there was a clear sense of the importance of the problem by people who can allocate substantial funds. Thus, while the resulting paper is clearly impactful, it was really the importance of the problem that mattered.

The second realm is to me the more interesting one. It reflects the impact of an article on how people think about research, or problems in policy and practice. Such an article need not be the result of a massive project designed to "answer" an important problem. Indeed, it may simply be an observation of a curiosity that leads one to reflect differently on the world. The problem with this criterion is that one can rarely see the import of such an article when it is published. Only in retrospect can it be determined, usually after many more articles have been published. (See, e.g., my review of the impact of Jack Wennberg's work on small area variations [Luft 2012].) The advantage for those pursuing this type of excellence is that it relies mostly on seeing things in new 
ways and presenting the findings compellingly - one need not have massive funding to produce such an article.

Jackie Zinn and Patrick Romano: Do you have any thoughts on ways HSR needs to evolve next to continue its leadership in the field? Going forward, where do you see the field headed?

Steve Shortell: The elephant in the room remains the nearly 18 percent of GDP devoted to the cost of health care. Further, the move toward value-based payment received strong bipartisan support and is likely to reshape the health care delivery system for years to come. Thus, one can predict that research simulating various changes in health insurance coverage, evaluating the impact of such changes including a possible move to block grants for the Medicaid program, and assessing the effects on health care equity will all be salient. On the delivery side, research that focuses on assessing the impact of bundled payments and related value-based payment reforms will continue. The evolution and performance of accountable care organizations (ACOs), the integration of behavioral health into primary care, the growing importance of the postacute sector, the impact of provider and insurer consolidation, and the growth of pharmaceutical costs will be important. One may also expect to see growing interest in research on transformational improvement initiatives such as Lean and Lean plus Six Sigma along with application of new digital technologies on health care delivery.

Aside from the above, there are three relatively new developments that will influence the research agenda. The first is the growing interdependence and permeability between the health care delivery sector and the broader human services sector associated with the social determinants of health, including education, transportation, housing, agriculture, and community development. As more delivery systems become accountable and at risk not only for the total cost and outcomes of care for their patients but for those in the community at large, there will be a growing research agenda on these new kinds of partnership arrangements sometimes called accountable communities for health (ACHs) or accountable health communities (AHCs). A second emerging area of investigation will involve the application of advances in genomics to diagnosis and treatment impacting the clinical encounter and the relationship between patients and their providers in all dimensions - from ethical to cost, quality, and outcome considerations. The third area is the growing recognition of the importance of context in health services research. Findings that hold in some settings with certain characteristics of, for example, size, ownership, geography, culture, and so on frequently do not hold up in other settings. Rather than simply considering these characteristics as control variables, research is needed on these variables themselves-their causes and 
consequences. The growing field of implementation science (with its own journal) is beginning to generate knowledge of such contextual factors as they influence intervention and program outcomes. I expect that in the future $H S R$ will be a likely outlet for some of the more important of these findings.

We also need to recognize that the nature of doing research is changing. Large-scale data sets are becoming more available. More research is being conducted in health services research centers of delivery systems themselves with the more immediate opportunity for application in changing and improving current practice. And with the growth of "big data" comes opportunities to apply the rapid advances in artificial intelligence (AI). Where theory, frameworks, logic models, hypotheses, and intuition fail to achieve the desired "purchase" on an issue, there is the ability to rapidly analyze large volumes of data to discover relevant patterns among variables of interest. In the HSR Methods Section, one can imagine an increase in articles that deal with AI applications.

As a final note, I suggest, perhaps somewhat counterintuitively, that $H S R$ can continue to provide leadership to the field by NOT being overly "current" or "topical." While many of the issues noted above should populate the pages of the Journal and generate actionable knowledge for policy makers and clinical and organizational leaders, space should also be devoted to the underlying determinants of individual, group, organizational, and institutional behavior in the health care sector. Examples include new developments in behavioral economics, social network theory/analysis, and the growing science of rapid learning systems. To ensure this, the Journal might consider developing a new section titled "New Theory Application" analogous to the current sections on Methods and Policy Impact.

Ann Flood: In these times, when even the President has become "Twitterpated" and willing to reduce the message to a few words, we may need to rethink the role of the printed issue and/or the importance of shorter sound bites. We seem to have already moved well beyond the usefulness of the printed issue for access to articles and need to reassess the value added by publishing in a specific journal. However, we should not renege on our mission to provide additional details about the theory and methodology compared to other journals and should identify when and why publishing in a specific journal brings value to our authors.

Maybe we should rethink whether and when printed issues are necessary for these purposes. Perhaps there would be a demand for printed issues that consist of special issues or "theme issues"-including themes created after the fact based on articles that spanned one or two years, for example, ones that would be useful compendia for teaching purposes. Options besides printed 
issues could still distinguish us from open-access journals and still allow our publisher to have access to revenues that undergird the basic model that authors do not need to "purchase" publication of their work. For example, authors could, after the fact of acceptance for publication, purchase rights to list their articles on scientific interchanges such as LinkedIn or ResearchGate.

It does seem time to reevaluate the model we have for providing access to published articles to be sure it is in line with the value added by our peer review process and our "brand" of Health Services Research.

Hal Luft: HSR has the opportunity to shift its current focus from a largely academic audience to a readership also interested in how research can inform changes to policy and practice. It could achieve this shift by using new dissemination platforms that are not only electronic but can be configured to be interactive. Thus, after the usual peer review process, which helps readers feel that the articles they read have been vetted (no "fake" research here), a new, electronic version of $H S R$, eHSR, would make it easy for readers to add signed comments to each article, probably with a bit of editorial oversight. Readers of eHSR could add links to other relevant articles, with supportive or conflicting findings. They could add examples of real-world applications of the research. Readers could find potential partners through common interest in the same article. As new things are added to the commentaries and suggestions associated with an $e H S R$ article, readers could be notified, bringing them back to work they had previously read and noted.

Creation of $e H S R$ would help the field become more relevant to the people with the problems many of us are trying to research. By fostering engagement between the problem holders and the researchers, each group will benefit. Policy makers, practitioners, and delivery system operational leaders will see what researchers have to offer, perhaps even leading them to directly or indirectly increase their financial support of the field. Researchers will better understand the problems faced by people in the "real world," leading to more nuanced and applicable research.

Jackie Zinn and Patrick Romano: Thanks to all of our former co-editors in chief for their thoughtful insights into where we have been and where we are going, as a journal and field.

\section{REFERENCES}

Flood, A. B., and M. L. Fennell. 1995. "Through the Lenses of Organizational Sociology: The Role of Organizational Theory and Research in Conceptualizing and 
Examining Our Health Care System.” Journal of Health and Social Behavior 36: 154-69.

Flood, A. B., W. R. Scott, and W. Ewy. 1984a. "Does Practice Make Perfect? I: The Relation between Hospital Volume and Outcomes for Selected Diagnostic Categories.” Medical Care 22 (2): 98-114.

1984b. "Does Practice Make Perfect? II: The Relation between Volume and Outcomes and Other Hospital Characteristics." Medical Care 22 (2): 115-24.

Luft, H. S. 2012. "From Small Area Variations to Accountable Care Organizations: How Health Services Research Can Inform Policy.” Annual Review of Public Health 33: 377-92.

Luft, H. S., J. Bunker, and A. Enthoven. 1979. "Should Operations Be Regionalized? An Empirical Study of the Relation between Surgical Volume and Mortality." Nerw England Journal of Medicine 301: 1364-69. Dec. 201979.

Luft, H. S., S. S. Hunt, and S. C. Maerki. 1987. "The Volume-Outcome Relationship: Practice Makes Perfect or Selective-Referral Patterns?” Health Services Research 22 (2): 157-82. 